\title{
Association of adrenomedullin gene polymorphisms and blood pressure in a Chinese population
}

\author{
Shufeng Chen ${ }^{1}$, Xiangfeng Lu${ }^{1}$, Qi Zhao ${ }^{2}$, Laiyuan Wang ${ }^{1,3}$, Hongfan $\mathrm{Li}^{1}$ and Jianfeng Huang ${ }^{1}$ \\ Genetic factors may determine an individual's blood pressure (BP) level and risk for hypertension. This study aimed to examine \\ the associations between genetic variants of the adrenomedullin ( $A D M$ ) gene and essential hypertension, as well as BP levels, \\ in a Chinese Han population. In this study, 2410 hypertensive patients and 2346 normal controls were recruited. Three \\ tagging single-nucleotide polymorphisms (SNPs) based on the HapMap CHB data were selected and genotyped. No significant \\ associations between the three SNPs of the ADM gene and hypertension status were observed. However, SNP rs4399321 \\ was found to be associated with BP levels among the controls. GG homozygotes for this SNP had higher systolic BP (SBP) \\ levels than carriers of the $A$ allele $(P=0.002)$. Particularly in non-drinkers, $G G$ homozygotes had significantly higher SBP \\ (116.9 \pm 0.9 vs. $113.7 \pm 0.3 \mathrm{~mm} \mathrm{Hg}, P=0.001)$ and diastolic $(74.0 \pm 0.7$ vs. $72.6 \pm 0.2 \mathrm{~mm} \mathrm{Hg}, P=0.046)$ BP levels than \\ carriers of the A allele. Neither rs4910118 nor rs7944706 was associated with BP levels in the controls either before or after \\ being stratified by drinking status. The results of this study showed that genetic variations in the ADM gene were not associated \\ with the risk of hypertension in a Chinese population. However, the genotype at common variation rs4399321 may influence \\ the BP level in normotensive subjects, especially among non-drinkers. In addition, replications in other populations and further \\ functional studies are required to confirm and interpret the association of $A D M$ with $\mathrm{BP}$. \\ Hypertension Research (2013) 36, 74-78; doi:10.1038/hr.2012.132; published online 30 August 2012
}

Keywords: adrenomedullin; alcohol drinking; tagging SNP

\section{INTRODUCTION}

Hypertension is characterized by a chronic elevation of blood pressure (BP) and affects $26.4 \%$ of the world's adult population. ${ }^{1}$ Elevated BP has a continuous and graded impact on cardiovascular disease risk and is a major contributor to cardiovascular deaths. ${ }^{2}$ Approximately $20-40 \%$ of the variation in BP in the general population is determined by genetic factors. ${ }^{3,4}$ Until now, the genetic structure of $\mathrm{BP}$ regulation and hypertension has not been fully understood.

Adrenomedullin (ADM), a potent hypotensive peptide consisting of 52 amino-acid residues, was originally isolated from human pheochromocytoma tissue, ${ }^{5}$ but it is widely distributed throughout the cardiovascular system. ${ }^{6,7} \mathrm{ADM}$ has several potential roles in a variety of cardiovascular pathologies. It causes vasodilatation and increases cardiac output and left ventricular contractility in vivo. ${ }^{8,9}$ The plasma ADM level increases in patients with hypertension, renal failure and congestive heart failure. ${ }^{10-12}$ In healthy volunteers, the infusion of ADM produced significant hemodynamic effects, inhibited aldosterone secretion and activated the sympathetic system. ${ }^{13}$ Moreover, midregional proadrenomedullin levels have been recently reported to predict future coronary events in a population-based prospective cohort study. ${ }^{14}$
In humans, the $A D M$ gene maps to chromosome 11p15.4. A microsatellite marker of cytosine adenine repeats $(\sim 5.4 \mathrm{~kb}$ downstream of the $3^{\prime}$ end of the $A D M$ gene) was associated with hypertension in a Japanese population. ${ }^{15}$ In another Japanese population, this microsatellite marker and other two single-nucleotide polymorphisms (SNPs), rs4399321 and rs7944706, were not associated with hypertension. ${ }^{16}$ SNP -1984 G/A (rs3814700) in the ADM gene was associated with systolic BP (SBP) and pulse pressure in a familybased Chinese population study. ${ }^{17}$ These inconsistent findings might result from small sample sizes and limited statistical power. Further studies are necessary to clarify the association between this gene and hypertension. The aim of this study was to investigate the association of genetic variants in the $A D M$ gene with the risk of essential hypertension and with the BP level using a large Chinese Han population sample.

\section{METHODS}

Subjects

All participants in this study were from the International Collaborative Study of Cardiovascular Disease in Asia (InterASIA in China). ${ }^{18}$ InterASIA selected a nationally representative sample of the general population aged 35-74 years in

${ }^{1}$ State Key Laboratory of Cardiovascular Disease, National Center for Cardiovascular Diseases, Division of Population Genetics, Department of Evidence Based Medicine, Fuwai Hospital, Chinese Academy of Medical Sciences and Peking Union Medical College, Beijing, China; ${ }^{2}$ Department of Epidemiology, School of Public Health and Tropical Medicine, Tulane University, New Orleans, LA, USA and ${ }^{3}$ Chinese National Human Genome Center at Beijing, Beijing, China

Correspondence: Dr S Chen, State Key Laboratory of Cardiovascular Disease, National Center for Cardiovascular Diseases, Division of Population Genetics, Department of Evidence Based Medicine, Fuwai Hospital, Chinese Academy of Medical Sciences and Peking Union Medical College, 167 Beilishi Road, Beijing 100037, China. E-mail: shufengchen2001@yahoo.com.cn

Received 28 April 2012; revised 17 June 2012; accepted 2 July 2012; published online 30 August 2012 
China. A total of 15838 persons completed the survey and examination. Three BP measurements were obtained from each participant by trained and certified observers according to a standard protocol recommended by the American Heart Association. ${ }^{19}$ In this study, hypertensive cases were selected based on an average SBP $\geqslant 150 \mathrm{~mm} \mathrm{Hg}$ and/or diastolic BP (DBP) $\geqslant 95 \mathrm{~mm} \mathrm{Hg}^{20}$ or the current use of antihypertensive medications. The control subjects had $\mathrm{SBP}<140 \mathrm{~mm} \mathrm{Hg}, \mathrm{DBP}<90 \mathrm{~mm} \mathrm{Hg}$ and no history of hypertension. Subjects with secondary hypertension, coronary heart disease and diabetes were excluded from this study. The cases and controls were matched for age, gender and area of residence. A total of 4756 subjects (2410 cases and 2346 controls) were included in the current study. Smoking is defined as cigarette consumers who have smoked more than 100 cigarettes. Drinking is defined as alcohol consumers who drank more than 12 times during the year prior to the interview. All subjects were unrelated Han Chinese. Body weight and height were measured twice in light indoor clothing without shoes. Body mass index (BMI) was calculated as weight in kilograms divided by the square of height in meters. The local bioethical committee approved the study protocol, and informed consent was obtained from each participant.

Blood samples were drawn after an overnight fast, and the serum was segregated for biochemical analysis within $2 \mathrm{~h}$. All samples were stored at $-70{ }^{\circ} \mathrm{C}$. Serum total cholesterol (TC), triglycerides (TG), high-density lipoprotein cholesterol (HDL-C) and glucose were measured on a Hitachi 7060 automatic analyzer (Hitachi, Tokyo, Japan) by enzymatic methods. The concentration of low-density lipoprotein cholesterol (LDL-C) was calculated by Friedewald's equation for participants who had a TG level $<400 \mathrm{mg} \mathrm{dl}^{-1}$ $($ LDL-C $=$ TC-HDL-C- $[\mathrm{TG} \div 5]){ }^{21}$ The Lipid Research Laboratory of the Disease Control and Prevention Center (Atlanta, GA, USA) provided serum for quality controls.

\section{SNP selection and genotyping}

Genomic DNA was isolated from peripheral blood leukocytes by the standard method. The $A D M$ gene spans $2.28 \mathrm{~kb}$ and comprises four exons and three introns. We searched the HapMap CHB data (http://www.hapmap.org, Rel 27) and selected common SNPs (minor allele frequency $>5 \%$ ) within a $10-\mathrm{kb}$ region spanning the $A D M$ gene (including the 3.86-kb flanking regions each upstream and downstream of the gene). Three tagging SNPs were selected using Haploview software (version 4.2, http://www.broad.mit.edu/mpg/haploview). Sets of tagging SNPs resolving the common haplotypes were selected at an $r^{2}$ threshold of 0.8 . The SNPs were genotyped by the polymerase chain reaction and restriction fragment length polymorphism method. The following primers were used for genotyping: $5^{\prime}$-ATTGGAATGTGAAGAAGTTGA- $3^{\prime}$

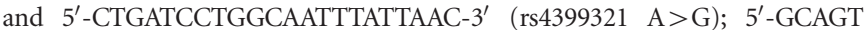
ACGTGCGGTT TAATAAGT $-3^{\prime}$ and $5^{\prime}$-TATGTCCCCTGCCTTTCTAGTC- $3^{\prime}$ (rs4910118 C > T); 5'-AGACATGTGCGAGGAGACAGAGA-3' and $5^{\prime}$-CCCG TGTTTGATTACAAATGTATGGTAGCA-3' (rs7944706 G>A), containing one single-base mismatch (underlined). The PCR products for the three polymorphisms were digested overnight at $37^{\circ} \mathrm{C}$ with HaeIII, Cfr42I and Mva1269I, followed by detection on $2-3 \%$ ethidium bromide-stained agarose gels.

\section{Statistical analysis}

The clinical characteristics were compared between hypertensive patients and normotensive subjects. Genetic association analyses were conducted for each of the tagging SNPs in codominant, dominant and recessive models, respectively. Logistic regression analysis was applied to adjust for multiple covariates including age, gender, BMI, smoking and drinking status. The Haplo.score program was used to test for the association of statistically inferred haplotypes with hypertension. ${ }^{22}$ It is based on score statistics, which provides both global tests and haplotype-specific tests. Haplo.glm was used to compute the regression of a trait on haplotypes and other covariates. Both Haplo.score and Haplo.glm were implemented in the Haplo.stats software using the $\mathrm{R}$ language (http://www.r-project.org). Only the haplotypes with frequencies $>1 \%$ were considered in the haplotype analyses. The associations between the SNPs and absolute BP levels were tested in the control group and in the hypertensive patients who did not take antihypertensive medications in the past 2 weeks before the study examination. A general linear model was used to adjust for multiple covariates, including age, gender, BMI, smoking and drinking status. Given the fact that environmental factors may modify the effect of genetic factors on BP regulation, we further included the interaction terms of SNPs and smoking or drinking status in the linear models. Descriptive statistical analyses were conducted using SAS software (version 9.1, SAS Institute Inc., Cary, NC, USA). The extent of pairwise linkage disequilibrium between the SNPs and Hardy-Weinberg equilibrium was tested using Haploview software (version 4.2, http://www.broad.mit.edu/mpg/haploview). All statistical tests were two-tailed, and a $P<0.05$ was considered statistically significant.

\section{RESULTS}

The distribution of the clinical and biological characteristics of the cases and controls are given in Table 1. Compared with the controls, the patients with hypertension had a significantly higher BMI, BP level and serum concentrations of fasting glucose, TG, TC, LDL-C and a lower concentration of HDL-C. The proportions of smokers and drinkers in the patients were similar to those in the control group.

The genotype distribution for each polymorphism was in HardyWeinberg equilibrium. There were no significant differences in the genotypic and allelic distributions for each SNP between the case and control groups (Table 2). After adjusting for the effects of covariates in the logistic regression model, no association was found between each SNP and hypertension in the codominant, dominant or recessive models (data not shown). There were four major haplotypes with frequencies of $>1 \%$, and the haplotype A-C-A was the most common type in this study population (Table 3 ). The haplotype-based test was performed using the Haplo.stats program. In the Haplo.score analysis, the adjusted global score statistic was $3.36(P=0.50)$, which was close to the empirical $P$-value based on 1000 simulation repetitions (sim$P=0.33$ ). Compared with the reference haplotype A-C-A, three other haplotypes did not influence the risk of hypertension before or after adjusting for age, gender, BMI, smoking and drinking status.

In addition, we also examined the association between the three SNPs and absolute BP levels using a general linear model in the case and control groups. In the control group, no association was observed between the BP level and SNP rs4910118 or rs7944706. However, for SNP rs4399321, normotensive individuals who were homozygous for the minor $G$ allele had a higher SBP level than the carriers of the A allele $(116.3 \pm 0.7$ vs. $113.9 \pm 0.2 \mathrm{~mm} \mathrm{Hg}, P=0.002)$. Further analyses revealed that there might be an interactive effect of SNP rs4399321 and drinking status on the DBP $(P=0.041)$, but not the SBP

\section{Table 1 Comparison of clinical characteristics between cases and} controls

\begin{tabular}{|c|c|c|c|}
\hline & Control $(n=2346)$ & Case $(n=2410)$ & P-value \\
\hline Gender(M/F) & $1197 / 1149$ & $1206 / 1204$ & 0.50 \\
\hline Age (years) & $54.2 \pm 9.3$ & $54.6 \pm 10.1$ & 0.13 \\
\hline $\mathrm{SBP}(\mathrm{mm} \mathrm{Hg})$ & $114.1 \pm 10.2$ & $148.7 \pm 21.6$ & $<0.0001$ \\
\hline $\mathrm{DBP}(\mathrm{mm} \mathrm{Hg})$ & $73.0 \pm 7.5$ & $90.4 \pm 12.1$ & $<0.0001$ \\
\hline BMI $\left(\mathrm{kg} \mathrm{m}^{-2}\right)$ & $23.2 \pm 3.4$ & $25.2 \pm 3.7$ & $<0.0001$ \\
\hline TC $\left(\mathrm{mgdl}^{-1}\right)$ & $190.6 \pm 38.4$ & $198.4 \pm 37.5$ & $<0.0001$ \\
\hline $\mathrm{TG}\left(\mathrm{mg} \mathrm{dl} \mathrm{l}^{-1}\right)$ & $125.0 \pm 74.6$ & $148.4 \pm 92.4$ & $<0.0001$ \\
\hline HDL-C (mg dl-1) & $51.1 \pm 12.6$ & $49.2 \pm 12.7$ & $<0.0001$ \\
\hline LDL-C $\left(\mathrm{mg} \mathrm{dl}^{-1}\right)$ & $115.0 \pm 34.0$ & $120.5 \pm 33.9$ & $<0.0001$ \\
\hline Glucose (mgdl-1) & $95.2 \pm 14.0$ & $98.9 \pm 18.0$ & $<0.0001$ \\
\hline Smokers (\%) & $951(40.5)$ & 915 (38.0) & 0.07 \\
\hline Drinkers (\%) & $715(30.5)$ & $749(31.1)$ & 0.65 \\
\hline
\end{tabular}

Abbreviations: BMI, body mass index; DBP, diastolic blood pressure; F, female; HDL-C, highdensity lipoprotein cholesterol; LDL-C, low-density lipoprotein cholesterol; M, male; SBP, systolic blood pressure; TC, total cholesterol; TG, triglyceride. Values are mean \pm s.d. 
Table 2 Genotype and allele frequencies of three ADM gene polymorphisms

\begin{tabular}{|c|c|c|c|}
\hline Genotype/allele & Case (\%) & Control (\%) & P-value \\
\hline \multicolumn{4}{|l|}{ rs4399321 } \\
\hline$A A$ & $1283(54.9)$ & $1326(55.3)$ & \\
\hline$A G$ & $884(37.8)$ & 907 (37.9) & \\
\hline GG & $170(7.3)$ & $163(6.8)$ & 0.81 \\
\hline A allele & $3437(74.0)$ & $3501(74.4)$ & \\
\hline G allele & 1209 (26.0) & 1207 (25.6) & 0.67 \\
\hline \multicolumn{4}{|l|}{ rs4910118b } \\
\hline $\mathrm{CC}$ & $1381(59.2)$ & $1384(57.9)$ & \\
\hline $\mathrm{TC}$ & 832 (35.7) & $871(36.4)$ & \\
\hline TT & $120(5.1)$ & $137(5.7)$ & 0.53 \\
\hline C allele & $3578(77.0)$ & $3600(76.0)$ & \\
\hline T allele & $1068(23.0)$ & $1138(24.0)$ & 0.24 \\
\hline \multicolumn{4}{|l|}{ rs7944706 } \\
\hline $\mathrm{GG}$ & $667(28.5)$ & 689 (28.8) & \\
\hline $\mathrm{GA}$ & 1152 (49.2) & $1144(47.8)$ & \\
\hline $\mathrm{AA}$ & $521(22.3)$ & $562(23.4)$ & 0.52 \\
\hline G allele & 2469 (53.2) & 2495 (52.6) & \\
\hline A allele & 2175 (46.8) & $2253(47.4)$ & 0.55 \\
\hline
\end{tabular}

aGenotype was missing for 9 controls and 14 cases.

bGenotype was missing for 13 controls and 18 cases.

${ }^{\mathrm{c}}$ Genotype was missing for 6 controls and 15 cases.

Table 3 Association between ADM gene haplotypes and essential hypertension

\begin{tabular}{|c|c|c|c|c|c|c|c|c|}
\hline \multirow[b]{2}{*}{ Haplotype ${ }^{a}$} & \multicolumn{3}{|c|}{ Frequency } & \multicolumn{3}{|c|}{ Haplo.score } & \multicolumn{2}{|l|}{ Haplo.glm } \\
\hline & $A / l$ & Case & Control & Score & P-value & Sim-P & OR $(95 \% \mathrm{Cl})$ & $\mathrm{P}$-value \\
\hline$A-C-A^{c}$ & 0.462 & 0.464 & 0.461 & 0.301 & 0.76 & 0.75 & 1 & - \\
\hline $\mathrm{G}-\mathrm{C}-\mathrm{G}$ & 0.248 & 0.244 & 0.252 & -0.885 & 0.38 & 0.36 & $0.96(0.87-1.06)$ & 0.89 \\
\hline A-T-G & 0.229 & 0.232 & 0.225 & 0.780 & 0.42 & 0.43 & $1.03(0.93-1.14)$ & 0.49 \\
\hline$A-C-G$ & 0.048 & 0.046 & 0.051 & -1.237 & 0.22 & 0.21 & $0.89(0.73-1.08)$ & 0.30 \\
\hline
\end{tabular}

Abbreviations: $\mathrm{Cl}$, confidence interval; $\mathrm{OR}$, odd ratio.

Haplotypes with frequencies $<0.01$ are not included in the table. These four haplotypes cover $98.7 \%$ of existing haplotypes.

aLoci are arranged in the order rs4399321-rs4910118-rs7944706.

${ }^{b}$ Age, gender, body mass index, smoking and drinking statuses were adjusted.

${ }^{\mathrm{C}} \mathrm{A}-\mathrm{C}-\mathrm{A}$ was chosen to be the baseline haplotype.

$(P=0.137)$ level in controls. We further conducted stratified analyses according to drinking status (Figure 1). In normotensive nondrinkers, we observed that the subjects homozygous for the minor $\mathrm{G}$ allele had a significantly higher SBP $(116.9 \pm 0.9$ vs. $113.7 \pm 0.3 \mathrm{~mm} \mathrm{Hg}$, $P=0.001)$ and $\mathrm{DBP}(74.0 \pm 0.7$ vs. $72.6 \pm 0.2 \mathrm{~mm} \mathrm{Hg}, P=0.046)$ than the carriers of the A allele. There was no association between rs4399321 and BP levels in normotensive drinkers. In addition, we did not observe any significant association between these SNPs and $\mathrm{BP}$ levels in the hypertensive patients who were not taking antihypertensive medications.

\section{DISCUSSION}

Essential hypertension is a multifactorial disorder that involves the additive effects of many genes, each of which has a moderate effect on the development of hypertension. ${ }^{23}$ These genetic determinants interact with environmental factors to produce the final disease phenotype. SNPs can confer a genetic predisposition toward various complex diseases. In this large case-control study, we investigated whether $A D M$ gene variations were associated with hypertension and BP levels in a Chinese Han population. We found a significant association between SNP rs4399321 and BP level in the control subjects, particularly in non-drinkers.

Vascular cells, such as endothelial cells and smooth muscle cells, can produce and secrete ADM. ${ }^{24,25} \mathrm{ADM}$ is a strong vasodilatory peptide that has a wide range of biological actions related to vascular functions. In humans, $\mathrm{ADM}$ can reduce total peripheral resistance, lowering BP level and increasing heart rate. ${ }^{26} \mathrm{ADM}$ exerts its biological activity by combining with specific receptor complexes composed of the calcitonin receptor-like receptor and receptoractivity modifying proteins (RAMP), which has three subtypes (RAMP1-3). ADM modulates BP through both central ${ }^{27}$ and peripheral $^{28}$ mechanisms. ADM has been reported to induce nitric oxide production by activating phosphatidylinositol 3-kinase and Akt via the $\mathrm{Ca}^{2+} /$ calmodulin-dependent pathway, which then induces endothelium-dependent vasodilation. ${ }^{29}$ There was a significant correlation independent of age and BP between the plasma ADM level and pulse wave velocity. ${ }^{30}$ Plasma levels of ADM are correlated with BP increases in hypertensive patients and thus with disease severity. ${ }^{31} \mathrm{ADM}$ inhibits hypertrophy in cultured cardiomyocytes. ${ }^{32}$

In a Japanese study, there was no association of rs4399321 or rs7944706 of the $A D M$ gene with hypertension. ${ }^{16}$ In a small, familybased Chinese population study, SNP rs3814700 of the ADM gene is associated with SBP and sodium excretion. ${ }^{17}$ In this study, we did not examine rs3814700 directly, but we genotyped one of its proxy SNPs, rs4399321. The $r^{2}$ between these two SNPs is 0.94 in the HapMap Chinese $(\mathrm{CHB})$ population (Figure 2). We found an association between rs4399321 and BP level in this studied population.

The results of this study indicate an interaction between rs4399321 and drinking status on the BP level. Among non-drinkers, GG homozygotes had higher BP levels than A allele carriers. These results indicated that the $\mathrm{G}$ allele might have different roles in BP regulation according to the absence or presence of alcohol drinking. In rats, chronic ethanol intake increased the mRNA levels of pre-pro-ADM and reduced ADM-induced relaxation in the vasculature. ${ }^{33,34}$ Because of the protective and beneficial role of ADM on the cardiovascular system, increased $\mathrm{ADM}$ expression could act as a compensatory response to cardiovascular injuries or dysfunction induced by ethanol. In fact, ethanol altered mRNA expression by activating different pathways and was associated with both increases and decreases in mRNA levels. ${ }^{35}$ In addition, the effect of ethanol on the cardiovascular system is dose-dependent. ${ }^{36}$ Thus, the discrepancies observed for alcohol drinking may mask the influence of individual variants of this polymorphism in our study population. Our results provide evidence for an interactive effect between one common SNP in the $A D M$ gene and alcohol drinking on $\mathrm{BP}$, with a demonstrable difference in the individual SNP effects according to drinking status. The specific mechanism underlying this interaction is unknown, and further studies are warranted.

To speculate on the possible function of SNP rs4399321, we investigated its structure using TESS (http://www.cbil.upenn.edu/ cgi-bin/tess/tess), a web tool for predicting transcription element binding sites in DNA sequences. The TESS analysis showed that rs4399321 lies in a recognition sequence of the transcription element retinoic acid receptor- $\gamma$ and may alter transcription of the $A D M$ gene. Retinoic acid receptor can activate transcription by binding to retinoic acid-response elements in the promoters of primary target genes. This analysis suggests that SNP rs4399321 may act as a transcriptional 

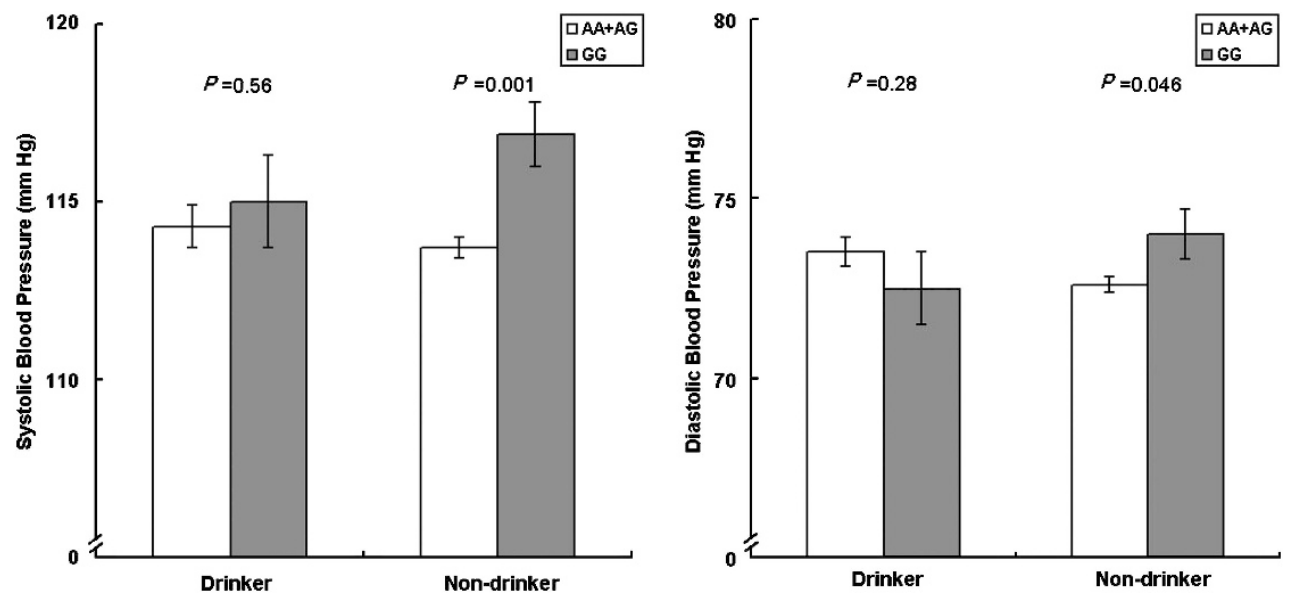

Figure 1 Systolic and diastolic blood pressure levels according to the rs4399321 genotypes of the ADM gene stratified by drinking status in controls. Covariates, including age, gender, body mass index, smoking and drinking status, were adjusted when appropriate. The values are the mean with standard error bars.

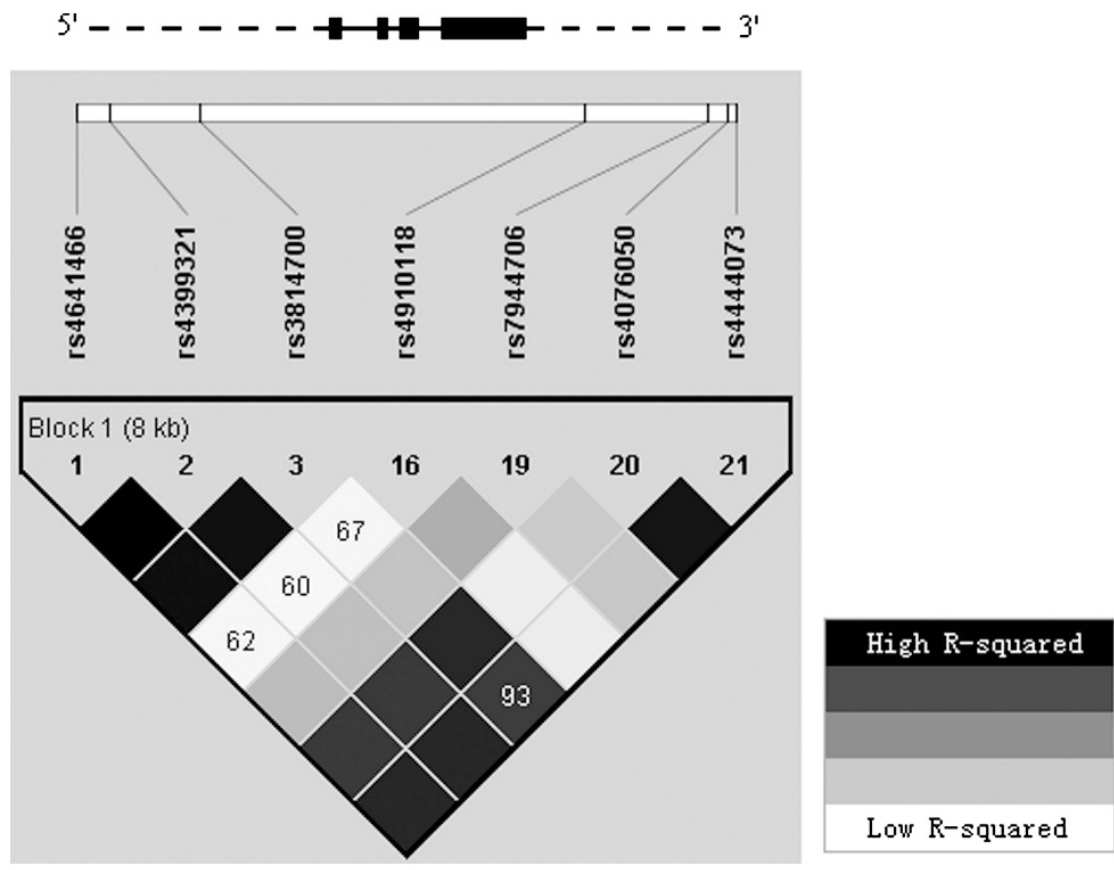

Figure 2 Linkage disequilibrium structure of the $A D M$ gene in the Chinese population HapMap sample. The black boxes in the ADM gene are exons. The solid lines show introns, and the dashed lines show the flanking regions. The numbers inside the squares are $D^{\prime} \times 100$ ( $D^{\prime}$ values of 1.0 are not shown). The $r^{2}$ color scheme of Haploview was applied $\left(r^{2}=0\right.$ shown in white, $0<r^{2}<1$ shown in shades of gray, and $r^{2}=1$ shown in black). The solid spine linkage disequilibrium method, as implemented in the Haploview software, was used to define the linkage disequilibrium blocks.

regulatory factor contributing to the development and occurrence of essential hypertension. Thus, functional studies to determine whether this SNP regulates the transcription of the $A D M$ gene are warranted. Certainly, we still cannot exclude the possibility that this SNP is in strong linkage disequilibrium with the true functional variation, which was not analyzed in the current study.

The major limitation of our study is that we did not examine the plasma concentration of ADM in participants. A recent study showed that SNP rs4910118 was independently associated with the plasma ADM level. ${ }^{37}$ Thus, we may not estimate the effect of these genetic variations on the plasma level of ADM and not detect their true effects on essential hypertension. Second, although rs4399321 was associated with the BP level, we failed to observe the association of this SNP with hypertension. In addition, we did not observe any significant associations between rs4399321 and BP levels in the cases. This negative finding may be due to the decreased power caused by excluding the patients who were treated with antihypertensive medications. Future studies with larger sample sizes are warranted to clarify the actual role of this SNP in BP regulation. However, this study also has two important strengths. First, in addition to the large sample size and ethnically homogeneous study population, tagging SNPs with relatively high minor allele frequency were selected to 
further increase the power to detect modest effect sizes. Second, we identified an interaction between the $A D M$ gene and alcohol drinking in the regulation of BP.

In summary, our study suggests that genetic variation in the $A D M$ gene may influence the BP level in a Chinese Han population. Furthermore, this study provided evidence that interactions between $A D M$ genotype and drinking status influenced $\mathrm{BP}$ levels. These findings will potentially contribute to a better understanding of the mechanism of BP control. In addition, independent replications of these findings and further functional investigations are warranted in the future.

\section{CONFLICT OF INTEREST}

The authors declare no conflict of interest.

\section{ACKNOWLEDGEMENTS}

This work was supported by the National Basic Research Program of China (grant no. 2011CB503901), the National High Technology Research and Development Program of China (grant no. 2012AA02A516) and the National Natural Science Foundation of China (grant no. 30600357).

1 Kearney PM, Whelton M, Reynolds K, Muntner P, Whelton PK, He J. Global burden of hypertension: analysis of worldwide data. Lancet 2005; 365: 217-223.

2 Lawes CM, Vander Hoorn S, Rodgers A. Global burden of blood-pressure-related disease, 2001. Lancet 2008; 371: 1513-1518.

3 Choh AC, Czerwinski SA, Lee M, Demerath EW, Wilson AF, Towne B, Siervogel RM Quantitative genetic analysis of blood pressure response during the cold pressor test. Am J Hypertens 2005; 18: 1211-1217.

4 Gu C, Borecki I, Gagnon J, Bouchard C, Leon AS, Skinner JS, Wilmore JH, Rao DC Familial resemblance for resting blood pressure with particular reference to racia differences: preliminary analyses from the HERITAGE Family Study. Hum Biol 1998; 70: 77-90.

5 Kitamura K, Sakata J, Kangawa K, Kojima M, Matsuo H, Eto T. Cloning and characterization of cDNA encoding a precursor for human adrenomedullin. Biochem Biophys Res Commun 1993; 194: 720-725.

6 Kitamura K, Kangawa K, Kawamoto M, Ichiki Y, Nakamura S, Matsuo H, Eto T. Adrenomedullin: a novel hypotensive peptide isolated from human pheochromocytoma. Biochem Biophys Res Commun 1993; 192: 553-560.

7 Sugo S, Minamino N, Shoji H, Kangawa K, Kitamura K, Eto T, Matsuo H. Production and secretion of adrenomedullin from vascular smooth muscle cells: augmented production by tumor necrosis factor-alpha. Biochem Biophys Res Commun 1994 203: 719-726.

8 Nishikimi T. Adrenomedullin in the kidney-renal physiological and pathophysiological roles. Curr Med Chem 2007; 14: 1689-1699.

9 Nishikimi T, Matsuoka H. Cardiac adrenomedullin: its role in cardiac hypertrophy and heart failure. Curr Med Chem Cardiovasc Hematol Agents 2005; 3: 231-242.

10 Nishikimi T, Horio T, Kohmoto $Y$, Yoshihara F, Nagaya $N$, Inenaga T, Saito M, Teranishi M, Nakamura M, Ohrui M, Kawano Y, Matsuo H, Ishimitsu T, Takishita S Matsuoka H, Kangawa K. Molecular forms of plasma and urinary adrenomedullin in normal, essential hypertension and chronic renal failure. J Hypertens 2001; 19: 765-773.

11 Ishimitsu T, Nishikimi T, Saito Y, Kitamura K, Eto T, Kangawa K, Matsuo H, Omae T, Matsuoka H. Plasma levels of adrenomedullin, a newly identified hypotensive peptide, in patients with hypertension and renal failure. J Clin Invest 1994; 94: 2158-2161.

12 Kato J, Kobayashi K, Etoh T, Tanaka M, Kitamura K, Imamura T, Koiwaya Y, Kangawa $\mathrm{K}$, Eto T. Plasma adrenomedullin concentration in patients with heart failure. J Clin Endocrinol Metab 1996; 81: 180-183.

13 Lainchbury JG, Troughton RW, Lewis LK, Yandle TG, Richards AM, Nicholls MG. Hemodynamic, hormonal, and renal effects of short-term adrenomedullin infusion in healthy volunteers. J Clin Endocrinol Metab 2000; 85: 1016-1020.

14 Melander O, Newton-Cheh C, Almgren P, Hedblad B, Berglund G, Engstrom G, Persson M, Smith JG, Magnusson M, Christensson A, Struck J, Morgenthaler NG, Bergmann A Pencina MJ, Wang TJ. Novel and conventional biomarkers for prediction of incident cardiovascular events in the community. JAMA 2009; 302: 49-57.

15 Ishimitsu T, Hosoya K, Tsukada K, Minami J, Futoh Y, Ono H, Ohrui M, Hino J, Kangawa K, Matsuoka H, Microsatellite DNA. Polymorphism of human adrenomedullin gene in normotensive subjects and patients with essential hypertension. Hypertension 2001; 38: 9-12.

16 Kobayashi Y, Nakayama T, Sato N, Izumi Y, Kokubun S, Soma M. Haplotype-based case-control study revealing an association between the adrenomedullin gene and proteinuria in subjects with essential hypertension. Hypertens Res 2005; 28 : 229-236.

17 Li Y, Staessen JA, Li LH, Gao PJ, Thijs L, Brand E, Brand-Herrmann SM, Zhu DL, Wang JG. Blood pressure and urinary sodium excretion in relation to the A-1984G adrenomedullin polymorphism in a Chinese population. Kidney Int 2006; 69 1153-1158.

18 Gu D, Reynolds K, Wu X, Chen J, Duan X, Muntner P, Huang G, Reynolds RF, Su S, Whelton PK, He J. Prevalence, awareness, treatment, and control of hypertension in china. Hypertension 2002; 40: 920-927.

19 Perloff D, Grim C, Flack J, Frohlich ED, Hill M, McDonald M, Morgenstern BZ. Human blood pressure determination by sphygmomanometry. Circulation 1993; 88: 2460-2470.

20 Chobanian AV, Bakris GL, Black HR, Cushman WC, Green LA, Izzo Jr JL, Jones DW, Materson BJ, Oparil S, Wright Jr JT, Roccella EJ. The Seventh Report of the Joint National Committee on Prevention, Detection, Evaluation, and Treatment of High Blood Pressure: the JNC 7 report. JAMA 2003; 289: 2560-2572.

21 Friedewald WT, Levy RI, Fredrickson DS. Estimation of the concentration of low-density lipoprotein cholesterol in plasma, without use of the preparative ultracentrifuge. Clin Chem 1972; 18: 499-502.

22 Schaid DJ, Rowland CM, Tines DE, Jacobson RM, Poland GA. Score tests for association between traits and haplotypes when linkage phase is ambiguous. Am $J$ Hum Genet 2002; 70: 425-434.

23 Lifton RP, Jeunemaitre X. Finding genes that cause human hypertension. J Hypertens 1993; 11: 231-236.

24 Ishihara T, Kato J, Kitamura K, Katoh F, Fujimoto S, Kangawa K, Eto T. Production of adrenomedullin in human vascular endothelial cells. Life Sci 1997 60: $1763-1769$.

25 Uemura T, Kato J, Kuwasako K, Kitamura K, Kangawa K, Eto T. Aldosterone augments adrenomedullin production without stimulating pro-adrenomedullin $\mathrm{N}$-terminal 20 peptide secretion in vascular smooth muscle cells. J Hypertens 2002; 20: 1209-1214.

26 Nagaya N, Satoh T, Nishikimi T, Uematsu M, Furuichi S, Sakamaki F, Oya H, Kyotani S Nakanishi N, Goto Y, Masuda Y, Miyatake K, Kangawa K. Hemodynamic renal, and hormonal effects of adrenomedullin infusion in patients with congestive heart failure. Circulation 2000; 101: 498-503.

27 Saita M, Shimokawa A, Kunitake T, Kato K, Hanamori T, Kitamura K, Eto T, Kannan H. Central actions of adrenomedullin on cardiovascular parameters and sympathetic outflow in conscious rats. Am J Physiol 1998; 274: R979-R984.

28 Jougasaki M, Wei CM. Aarhus LL, Heublein DM, Sandberg SM, Burnett JC Jr. Renal localization and actions of adrenomedullin: a natriuretic peptide. Am J Physiol 1995; 268: F657-F663.

29 Nishimatsu H, Suzuki E, Nagata D, Moriyama N, Satonaka H, Walsh K, Sata M Kangawa K, Matsuo H, Goto A, Kitamura T, Hirata Y. Adrenomedullin induces endothelium-dependent vasorelaxation via the phosphatidylinositol 3-kinase/Aktdependent pathway in rat aorta. Circ Res 2001; 89: 63-70.

30 Kita T, Kitamura K, Hashida S, Morishita K, Eto T. Plasma adrenomedullin is closely correlated with pulse wave velocity in middle-aged and elderly patients. Hypertens Res 2003; 26: 887-893.

31 Kohno M, Hanehira T, Kano H, Horio T, Yokokawa K, Ikeda M, Minami M, Yasunari K, Yoshikawa J. Plasma adrenomedullin concentrations in essential hypertension. Hypertension 1996; 27: 102-107.

32 Tsuruda T, Kato J, Kitamura K, Kuwasako K, Imamura T, Koiwaya Y, Tsuji T, Kangawa K, Eto T. Adrenomedullin: a possible autocrine or paracrine inhibitor of hypertrophy of cardiomyocytes. Hypertension 1998; 31: 505-510.

33 Hipolito UV, Rocha JT, Martins-Oliveira A, Tirapelli DP, Jacob-Ferreira A, Batalhao ME, Tanus-Santos JE, Carnio EC, Cunha TM, Queiroz RH, Tirapelli CR. Chronic ethano consumption reduces adrenomedullin-induced relaxation in the isolated rat aorta. Alcohol 2011; 45: 805-814.

34 Rocha JT, Hipolito UV, Martins-Oliveira A, Tirapelli DP, Batalhao ME, Carnio EC, Queiroz RH, Coelho EB, Cunha TM, Tanus-Santos JE, Tirapelli CR. Ethanol consumption alters the expression and reactivity of adrenomedullin in the rat mesenteric arteria bed. Alcohol Alcohol 2012; 47: 9-17.

35 Yeligar S, Tsukamoto H, Kalra VK. Ethanol-induced expression of ET-1 and ET-BR in liver sinusoidal endothelial cells and human endothelial cells involves hypoxia-inducible factor-1alpha and microrNA-199. J Immunol 2009; 183: 5232-5243.

36 Resstel LB, Tirapelli CR, Lanchote VL, Uyemura SA, de Oliveira AM, Correa FM Chronic ethanol consumption alters cardiovascular functions in conscious rats. Life SC 2006; 78: 2179-2187.

37 Cheung BM, Ong KL, Tso AW, Leung RY, Cherny SS, Sham PC, Lam TH, Lam KS. Plasma adrenomedullin level is related to a single nucleotide polymorphism in the adrenomedullin gene. Eur J Endocrinol 2011; 165: 571-577. 